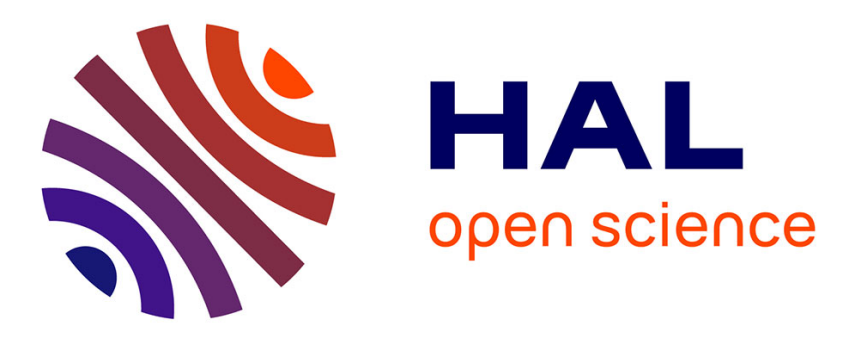

\title{
Age-dependent phenological plasticity in a wild bird
}

Suzanne Bonamour, Luis-miguel Chevin, Denis Réale, Céline Teplitsky, A.

Charmantier

\section{To cite this version:}

Suzanne Bonamour, Luis-miguel Chevin, Denis Réale, Céline Teplitsky, A. Charmantier. Agedependent phenological plasticity in a wild bird. Journal of Animal Ecology, 2020, 89 (11), pp.27332741. 10.1111/1365-2656.13337 . hal-02998152

\section{HAL Id: hal-02998152 \\ https://hal.science/hal-02998152}

Submitted on 23 Nov 2020

HAL is a multi-disciplinary open access archive for the deposit and dissemination of scientific research documents, whether they are published or not. The documents may come from teaching and research institutions in France or abroad, or from public or private research centers.
L'archive ouverte pluridisciplinaire HAL, est destinée au dépôt et à la diffusion de documents scientifiques de niveau recherche, publiés ou non, émanant des établissements d'enseignement et de recherche français ou étrangers, des laboratoires publics ou privés. 


\section{Age-dependent phenological plasticity in}

4

5

6

7

8

9

10

11

12

13

14

15

\section{a wild bird}

Suzanne Bonamour ${ }^{1}$, Luis-Miguel Chevin ${ }^{1}$, Denis Réale ${ }^{2}$, Céline Teplitsky ${ }^{1 *}$ and Anne Charmantier ${ }^{1 *}$

*Co-last authors

\section{Author's affiliation:}

${ }^{1}$ CEFE, Univ Montpellier, CNRS, EPHE, IRD, Univ Paul Valéry Montpellier 3, Montpellier, France.

2 Université du Québec à Montréal, Département des sciences biologiques, Case postale 8888, succursale Centre-ville, Montréal (Québec), H3C 3P8, Canada.

\section{Author for correspondence:}

Suzanne Bonamour

E-mail: suzannebonamour@protonmail.com 


\section{Abstract}

1. Life-history traits are often plastic in response to environmental factors such as temperature or precipitation, and they also vary with age in many species. Trait variation during the lifetime could thus be partly driven by age-dependent plasticity in these traits.

2. We study whether plasticity of a phenological trait - the egg-laying date - with respect to spring temperature, varies with age, and explore whether this variation relates to changes in breeding success throughout the life cycle.

3. We use data from a four-decade long-term monitoring of a wild population of blue tits in Corsica to estimate age-dependent plasticity of reproductive phenology and annual reproductive success.

4. We show that both laying date plasticity and annual reproductive success vary with age: young and old females are less plastic, and fledge fewer offspring, than middle-age females. Furthermore, in contrast to young and prime-age females, in old females fledging success does not depend on laying date.

5. Phenological plasticity is a major mechanism for coping with rapid environmental variation. Our results suggest that understanding its role in adaptation to climate change and population persistence requires integrating the age structure of the population.

Key words: Phenotypic plasticity, Laying date, Phenology, Aging, Passerines, Wild birds 
Phenotypic plasticity - the capacity of a given genotype to express different phenotypes according to environmental conditions (Pigliucci, 2001) - is a widespread phenomenon in nature (DeWitt \& Scheiner, 2004). Theoretical and empirical studies highlight the importance of phenotypic plasticity for population persistence (e.g. Ashander et al., 2016; Chevin et al., 2010; Reed et al., 2011). When plasticity is adaptive, it may allow the population mean phenotype to track an environment-dependent phenotypic optimum, thus minimizing the impact of environmental change on mean fitness and population growth. This is especially true for phenological traits, which determine the timing of key life history events such as reproduction, dormancy/diapause, or dispersal, synchronizing these events with the optimal timing set by a seasonal - and often also noisy - environment (e.g. Visser, 2008). Phenological traits have been shown to represent a major phenotypic response to rapid climate change (Davis et al., 2005; Parmesan \& Yohe, 2003; Radchuk et al., 2019; Visser \& Both, 2005; Walther et al., 2002). It is also increasingly clear that plastic changes contribute a large proportion of observed phenotypic change in the wild (e.g. Gienapp et al., 2007; Merilä \& Hendry, 2014; Walther et al., 2002), especially for phenological traits (Anne Charmantier \& Gienapp, 2014; Vedder et al., 2013).

Life-history traits (e.g. fecundity), in addition to often being phenotypically plastic, also vary with age in many iteroparous species. Empirical studies in vertebrates commonly show patterns of age-dependent reproductive performance, with increasing annual reproductive success in the beginning of life, followed by maximal reproductive performance in middle age, and finally, a decreasing success due to reproductive senescence (e.g. Balbontín et al., 2007; Clutton-Brock, 1988; Dingemanse et al., 2020; Warner et al., 2016). Since plastic phenology is a strong driver of reproductive performance in many species, notably in birds inhabiting temperate forests (e.g. Marrot et al., 2018; Perrins \& McCleery, 1989), it is likely that variation with age of phenological reaction norms underlies age-dependent patterns in reproductive success to some extent. If reaction norms vary with age, then 
understanding the role of plasticity in adaptation to rapid environmental change and population persistence requires integrating the age structure of the population (see e.g. van de Pol et al., 2012).

Theoretical studies on the evolution of age-dependent plasticity are still rare. They have focused so far on traits that are established once during development (developmental plasticity, according to West-Eberhard, 2003) in binary environments, and predict a decrease of plasticity with age (e.g. Fawcett \& Frankenhuis, 2015; Fischer et al., 2014; Stamps \& Krishnan, 2017). Formal theoretical predictions are still missing for traits that change repeatedly in life (labile traits), and with continuous expression under continuous environmental variation. But the general mechanisms responsible for an effect of senescence on plasticity, such as the decrease of selection strength with age (Charlesworth, 1993; Hamilton, 1966; Monaghan et al., 2008; Williams, 1957), should lead to a similar decrease in plasticity as individuals get older.

Within-individual variation of plasticity over the lifetime of individuals has been highlighted in some experimental studies, mainly in behavioural traits (e.g. Atwell \& Wagner, 2014; Ericsson et al., 2016), with highest plasticity in juveniles or young adults followed by decreasing plasticity with age, thus corroborating theoretical predictions. However, evidence is scarce for age-specific plasticity in wild populations. Araya-Ajoy \& Dingemanse (2016) compared the seasonal plasticity of aggressiveness in great tits (Parus major) between two age classes, and found that first-year-old breeders showed higher seasonal plasticity than older birds, also aligned with theoretical predictions. A study on phenological trait plasticity in superb fairywrens (Malurus cyaneus) demonstrated that the variation of moult timing with rainfall changed with age (van de Pol et al., 2012). Contrary to theoretical predictions, in this study older birds were more plastic than younger ones. Overall, the scarce empirical evidence means we still poorly understand the origin of age-dependent plasticity of labile phenotypic traits over a lifetime. The study of age-specific variation in plasticity in wild populations is an arduous task because of the combined challenges of studying phenotypic plasticity and senescence (Nussey et al., 2013; Nussey, Wilson, et al., 2007), both of which demand a long-term study with individual 
marking and repeated measures on the same individuals. In addition, plasticity estimation requires identifying the main environmental cue(s) explaining within-individual phenotypic variation (Gienapp, 2018). These challenges explain why age-specific variation of plasticity has been widely neglected so far in empirical studies.

We studied age-specific plasticity of a phenological trait, the egg-laying date, in a wild blue tit population. We used linear mixed models to explore the relationship between age-related plasticity and annual reproductive success across female lifetime. In this species, as in most temperate passerines, laying date varies plastically among years in response to spring temperature (e.g. Porlier et al., 2012). This variation allows birds to synchronize their reproductive period with the timing of maximal abundance of caterpillars, which constitute the main nutritive resource for nestlings (Blondel et al., 1991). Annual reproductive performances also vary with age in blue tits: young birds have low annual reproductive success (partially) due to inexperience (Gienapp \& Brommer, 2014), while old individuals suffer from reproductive senescence (Auld \& Charmantier, 2011). As a result, reproductive success increases and then decreases with age, with most traits peaking around 3 years of age. Since laying date is a plastic trait in response to temperature, age-related variation of reproductive timing and annual reproductive success could be associated with age-specific laying date plasticity with temperature. We expected a nonlinear variation of laying date plasticity with age. Plasticity should first increase in the early years of life, because of maturation and learning processes as suggested by an empirical study of Grieco et al. (2002). It should then decrease in old ages, because senescence is generally expected to lead to an overall decrease in performance. We expected similar quadratic agespecific variation in reproductive success.

\section{Materials \& Methods}

\section{Species and data collection}

We used a long-term study (initiated by Jacques Blondel in 1975) of a wild Mediterranean population of Blue tit (Cyanistes caeruleus ogliastrae), a small insectivorous and cavity-nesting passerine. Breeding 
dates were collected every spring on the study site. The population is on the island of Corsica, in an evergreen forest (E-Pirio population, $42^{\circ} 34^{\prime} \mathrm{N}, 08^{\circ} 44^{\prime} \mathrm{E}$ ) dominated by holm oaks (Quercus ilex) (see reviews on the long-term study in Blondel et al., 2006; Charmantier et al., 2016). Blue tits bred in 205 nest boxes (natural cavities are rare in this forest, Charmantier, pers. com.), which were monitored weekly from March to June to record laying date, clutch size and reproductive success. Breeding birds and nestlings were individually marked with a unique numbered metal ring.

We restricted our analyses to first broods of the season only (second broods represent less than c. $1 \%$ of the clutches). Age was estimated based on birth year for individuals born in nest boxes, or on plumage patterns for immigrants (see Supporting Information 1 Figure S1 for the number of females in each age class). Based on plumage patterns, captured immigrant females can be classified either as one year old (juvenile plumage), or two years or older (mature plumage pattern). In the present dataset, the exact age was known for c. $60 \%$ of females (corresponding to locally born and immigrant females first captured at one year old), while we used minimum age for the remaining $40 \%$ (corresponding to immigrant females first captured at two years or older). Dispersal in blue tits mainly happens before the first breeding event (i.e. natal dispersal, Greenwood \& Harvey, 1982; Matthysen et al., 2010), and the mortality rate in the focal population was high (about half of the individuals in each age class die every year, Dubuc-Messier et al., 2016). Hence the recruitment in the focal nest-box area of birds older than two years was likely to be uncommon (see Supporting Information 1 Figure S1). This suggests that allocating a minimum age of two years to immigrant females displaying adult plumage should lead to a low error rate in age estimation, as we confirmed by a sensitivity analysis (see Supporting Information 2).

Overall, the dataset contained 1696 laying date observations from 1976 to 2017, for 854 identified females (Supporting Information 1 Figure S1 and Table S1, Bonamour et al., 2020). The temperature cue was the average daily temperature between $31^{\text {st }}$ March and $7^{\text {th }}$ May, which is the 
period most correlated with inter-annual laying date variation at the population scale according to sliding-window analyses (Bonamour et al., 2019).

\section{Statistical analyses}

We estimated age-dependent laying date plasticity in response to temperature using the following linear mixed model (e.g. Nussey, Kruuk, et al., 2007),

$L D i j=\mu+\alpha_{1} T_{j}+\alpha_{2} A_{i j}+\alpha_{3} A_{i j}^{2}+\alpha_{4}\left(T_{j} A_{i j}\right)+\alpha_{5}\left(T_{j} A_{i j}^{2}\right)+\alpha_{6} A L R_{i}+$ ind $_{i}+$ year $_{j}+\varepsilon_{i j}$ (model 1)

where the laying date $L D\left(1=1^{\text {st }}\right.$ January $)$ of female $i$ in year $j$ is explained by several fixed effects: cue temperature $T_{j}$ of year $j$ (temperature was mean-centered across years), age $A_{i j}$ and age-squared $A_{i j}^{2}$ of female $i$ in year $j$ (with age a continuous variable ranking from 1 to 9 years old). The terms $T_{j} A_{i j}$ and $T_{j} A_{i j}^{2}$ are interactions estimating respectively the linear and quadratic age dependence of plasticity in laying date with temperature. We controlled for female longevity by adding an effect of age at last reproduction of female $i, A L R_{i}$, modelling a selective disappearance effect on laying date variation (e.g. Bouwhuis et al., 2009). To account for the non-independence of data collected on the same female and the same year, we included female identity $\left(i n d_{i}\right)$ and year $\left(y e a r_{j}\right)$ as random effects. The final term in model 1 is the residual error term $\varepsilon_{i j}$. Avian laying date is expressed by females, but can also be seen as a trait shared by the two sexes as some male characteristics may influence the timing of reproduction (e.g. Brommer \& Rattiste, 2008). However, in this population, a previous analysis detected no effect of male identity on breeding time (Auld \& Charmantier, 2011) and we thus restricted analyses to female birds. We also confirmed that there was no difference between the population- and individual-level plasticity (i.e. variation in laying date with temperature was not driven 
161

162

by between-female differences in reaction norm intercept across years), using the within-subject centering method (Supporting Information 3; van de Pol \& Wright, 2009).

We estimated the effects of age and laying date on annual reproductive success ARS (approximated as the number of fledglings per breeding attempt) using the following generalized linear mixed model,

$A R S_{i j}=\gamma+\beta_{1} A_{i j}+\beta_{2} A_{i j}^{2}+\beta_{3} L D_{i j}+\beta_{4}\left(A_{i j} L D_{i j}\right)+$ ind $_{i}+$ year $_{j}+r_{i j}$ (model 2)

where annual reproductive success $A R S_{i j}$ of female $i$ in year $j$ is explained by the female age $A_{i j}$ and age-square $A_{i j}^{2}$, the laying date $L D_{i j}$ and the interaction between laying date and age $\left(A_{i j} L D_{i j}\right)$. We included two random effects, female identity $\left(i n d_{i}\right)$ and year $\left(y e a r_{j}\right)$, and $r_{i j}$ are residuals. Annual reproductive success was not normally distributed (see Supporting Information 1 Figure S2), we thus ran the model as a generalized linear mixed model with a Poisson distribution. Females with clutch manipulation and all other experiments that could affect reproductive success were removed from the data set for model 2, reducing the dataset to 1092 laying date observations for 667 identified females. All statistical analyses were carried out using the software R (version 3.3.2, R Core Team, 2016), and performed in a Bayesian framework using a Markov Chain Monte Carlo estimation algorithm ( $R$ package MCMCgImm, Hadfield, 2010). For all random effects (including the residual variance), we used a weakly informative prior, corresponding to an inverse-Wishart $W^{-1}(\psi, v)$ distribution with $\psi$ equal to the phenotypic variance of laying date (or ARS variance, depending on the model 1 or 2 ) divided by the number of estimated variance components. $v$ is the degree of belief in the prior and we tested the robustness of results to the prior specification using $v=1,0.2$ or 0.02 . The default Gaussian noninformative prior in MCMCgImm with mean zero and variance $10^{8}$ was used for the fixed effects. Models were run for 1,010,000 iterations, including a burn-in period of 10,000 iterations. We ran three 
chains which were sampled every 1000 iteration to avoid autocorrelation. The maximum autocorrelation between estimates was $<0.05$ for fixed and random effects. Convergence of chains was tested using Gelman and Rubin's convergence diagnostic (Brooks \& Gelman, 1998; Gelman \& Rubin, 1992) and models converged well, with average Gelman's diagnostic $\hat{R}=1.00$ for fixed and random effects, comparing chains from different priors.

\section{Results}

Laying date varied within a female's lifetime, in response to both temperature and age (Table 1). Laying date was earlier with warmer springs, with a median value of c. 3 days earlier every $1^{\circ} \mathrm{C}$ warmer (Table 1, Figure 1a\&b). It also varied non-linearly with age, decreasing until age 4 and then increasing (Table 1, Figure 1a\&c). Our results suggested that shorter-lived females tend to breed later, but note that the 95\% credible interval in the posterior distribution of the ARS marginally included zero (Table 1, but see Supporting Information 2 Table S3).

We also found age-dependent plasticity in reproductive phenology. The response of laying date to temperature changed with age, as evidenced by the interaction between temperature and the linear age effect (Table 1). This resulted in reaction norm slopes getting steeper as female age increased, until c. 5 years old (Figure $1 \mathrm{~b} \& \mathrm{c}$ ). In addition, our results suggested that plasticity declines for older females (after 6 years old, Figure 1c); however small sample sizes for these late age classes resulted in large credible intervals (Table 1, Supporting Information 1 Figure S1). The largest difference in reaction norm slopes was between 1 year-old (i.e. yearling) and 5 year-old females: the estimated median slope of laying date reaction norm with respect to temperature was -3.68 days $/{ }^{\circ} \mathrm{C}( \pm 0.002, \mathrm{p}$ value $\left.<2.10^{\wedge} 16\right)$ for yearlings, and -4.94 days $/{ }^{\circ} \mathrm{C}\left( \pm 0.001, \mathrm{p}\right.$-value $\left.<2.10^{\wedge} 16\right)$ for 5 year-old females (Figure $1 \mathrm{~b}$ ), leading to a median difference of c. 1.5 days $/{ }^{\circ} \mathrm{C}$ between both age classes.

Annual reproductive success also varied with female age (Table 2). Model 2 revealed a quadratic relationship between annual reproductive success and age, such that young and especially old females displayed lower annual reproductive success than middle-age females (Table 2, Figure 2a). 
statistical evidence for an interaction between age and laying date (Table 2; preliminary analyses showed no evidence for an interaction between laying date and age-squared). Importantly, the relationship between laying date and reproductive success was negative for all ages except for females older than 5 years old (Figure 2b). Hence, despite low statistical power in old age classes (Supporting Information 1 Figure S1), these results suggest that reproductive success in old females was low independently of their laying date.

\section{Discussion}

To our knowledge, our study is the first to report age-dependent phenotypic plasticity of laying date with temperature. Laying date plasticity with spring temperature is a common pattern observed in many avian natural populations (e.g. Dunn, 2004; Visser et al., 2009). In temperate regions, this plasticity causes among-year variation in phenology, which allows synchronization between predators (birds) and their preys (in particular caterpillars, see e.g. Dunn, 2004; Van Noordwijk et al., 1995). Laying date variation with female age is likewise a well-known pattern in free-living as well as in controlled iteroparous animal populations (e.g. Auld \& Charmantier, 2011; Nussey et al., 2008), although the senescent delay in avian breeding phenology was only revealed in the last two decades. Similarly to previous investigations (Auld \& Charmantier, 2011), model 1 shows that young and old females lay later than middle-age birds (Table 1, Figure 1). laying date reaction norms is complex, as both the slope and intercept vary with female age (Table 1, Figure 1). This leads to a pattern whereby young and old females lay later on average (i.e. higher median reaction norm intercept), and the age-dependent reaction norm slope accentuates the phenological delay between young or old and middle-age females (Figure 1). For instance, in warm springs with temperature $1.5^{\circ} \mathrm{C}$ higher than average, the resulting median laying date is $\approx 5$ days earlier 
$13 \%$ of the total phenotypic range in laying date in the entire dataset (c. 39 days), while the among-

236 individual (averaged across years and environments) and among-year effects explain respectively about $28 \%$ (c. 11 days) and $36 \%$ (c. 14 days) of this range. extensive impacts on population dynamics and persistence in our short-lived passerine population, because females of 5 years and older represent only $8 \%$ of the total population (Supporting Information 1 Figure S1 and population annual adult survival probability of $c$. 0.5 , Dubuc-Messier et al., 2016). However, warmer springs in the future should lead to higher among-individual variation of laying date, as the influence of age-dependent plasticity on laying date variation becomes more marked (assuming no evolutionary change of laying date reaction norm).

Our results seem consistent with theoretical models of age-dependent plasticity (e.g. Fawcett \& Frankenhuis, 2015; Fischer et al., 2014; Stamps \& Krishnan, 2017) despite substantial differences between our blue tit biological model and some assumptions of the theoretical models. As predicted by theoretical studies, plasticity decreased at old ages in our study population. However, the pattern was complex, as we observed quadratic variation of both laying date plasticity (Table 1, Figure 1) and annual reproductive success (Table 2, Figure 2). From a more mechanistic perspective, Fawcett \& Frankenhuis (2015) highlight that age-dependent plasticity will evolve if there is variation across the lifetime of either i) cue reliability, ii) the relationship between fitness and the plastic response, or iii) constraints on the expression of phenotypic plasticity. First, we have no a priori reason to expect changes in cue reliability with female blue tit age: spring temperature should predict the caterpillar peak date independently of female age. However, the physiological ability to detect environmental cues such as temperature (Caro et al., 2013; Visser et al., 2009) or photoperiod (Dawson, 2008) may change with age. This could explain age-dependent plasticity, since the optimal reaction norm slope increases as a function of cue reliability (Gavrilets \& Scheiner, 1993), but little is known about changes in perception abilities with age in birds. Second, the fitness benefits associated with laying date 
plasticity may vary during female lifetime. For example, their foraging capacity may increase with age, leading to a reduced importance - for annual reproductive success - of the synchronisation between the peak of nutritive resources and bird reproductive timing in older females. In our population, such age-dependent fitness benefits of plasticity could not explain the increasing plasticity before 5 years old. However, the fitness advantage of earlier breeding seems to decrease in old ages (Figure 2b), which could lead to lower fitness benefits to being plastic and induce selection for reduced (assumed costly) plastic capacity in old female birds. Third, a learning process of plasticity early in life may explain variation in laying date plasticity. Grieco et al. (2002) showed that blue tits laid in the same period as their previous breeding season if they were supplied with additional food, but they laid earlier if they were short of nutritive resources. Such a pattern may explain increasing plasticity in young females, especially following warmer springs, when the caterpillar peak is earlier than the average. Finally, plasticity is expected to require resources, especially to acquire information to track environmental changes (Dewitt, 1998), which may lead to constraints on plastic capacity. Hence, yearlings may not have accumulated enough resources during their first winter to adequately modulate their laying date according to temperature, again especially in warmer years when breeding phenology is optimally early. In the same vein, old females suffering from reproductive senescence may not be able to display steeper plasticity because of lack of resources. Further investigations on the physiological conditions of young and old females are needed to better understand proximal causes of age-dependent plasticity.

To evaluate the fitness costs of a late laying date, which partially depends on a lack of plastic response to temperature, we analysed the relationships between laying date, age and a fitness component. We used an estimate of annual reproductive success - the number of fledglings - as fitness component. Results from model 2 and Figure 2 show that breeding too late decreases annual reproductive success for young and middle-age females but not for the oldest birds. In other words, plasticity of laying date, has no consequences on reproductive success of old females. This suggests that selection for plasticity could decrease with age in this population. Exploring whether the selection 
on laying date reaction norms changes with age, including the possibility that selection on laying date across environments (i.e. selection depending on temperature) causes indirect selection on its plasticity (e.g. Ramakers et al., 2018; van Tienderen \& Koelewijn, 1994) is an exciting perspective. However, such a study would require a data set much larger than ours based on 42 years of monitoring. A full understanding of these complex relationships between laying date, age and fitness would also require to investigate selection beyond fledging (e.g. through recruitment success) but also including lifetime reproductive success and/or survival, to integrate the potential fecundity-survival trade-offs.

\section{Conclusion and perspectives}

To conclude, this study reveals age-dependent plasticity of laying date in response to spring temperature in a wild blue tit population. Young and old females were less plastic than middle-aged females. Our results suggest that, unlike prime-age females, young females may have not reached their full reproductive capacities, while the older ones may no longer be subject to natural selection on laying date. Such age-dependent effects result in a quadratic variation of laying date plasticity. Considering the importance of plastic responses for population persistence in a rapidly changing world (Chevin et al., 2013; Reed et al., 2010), within-individual variability of plasticity has to be taken into account in studies of plasticity in the wild. Models of age-structured populations could help to comprehend how age-related plasticity impacts adaptation and population persistence. As chronic stress is known to speed up senescence (Hayward et al., 2009; Monaghan et al., 2008; Ricklefs, 2008), current global change could increase variation of plasticity with age, and its impact could be even stronger for phenological traits for which plasticity is an important component of response to climate change (Davis et al., 2005; Parmesan \& Yohe, 2003; Radchuk et al., 2019; Visser \& Both, 2005; Walther et al., 2002). We suggest that age-specific phenological plasticity should be studied in other systems, particularly in long-lived species, to get a fuller understanding of the importance of within-individual variation in plasticity for population persistence in nature. 


\section{References}

Araya-Ajoy, Y. G., \& Dingemanse, N. J. (2016). Repeatability, heritability, and age-dependence in the aggressiveness reaction norms of a wild passerine bird. Journal of Animal Ecology, 227-238. https://doi.org/10.1111/1365-2656.12621

Ashander, J., Chevin, L.-M., \& Baskett, M. L. (2016). Predicting evolutionary rescue via evolving plasticity in stochastic environments. Proceedings of the Royal Society B: Biological Sciences, 283(1839), 20161690. https://doi.org/10.1098/rspb.2016.1690

Atwell, A., \& Wagner, W. E. (2014). Female mate choice plasticity is affected by the interaction between male density and female age in a field cricket. Animal Behaviour, 98, 177-183. https://doi.org/10.1016/j.anbehav.2014.10.007

Auld, J. R., \& Charmantier, A. (2011). Life history of breeding partners alters age-related changes of reproductive traits in a natural population of blue tits. Oikos, 120(8), 1129-1138. https://doi.org/10.1111/j.1600-0706.2010.19161.x

Balbontín, J., Hermosell, I. G., Marzal, A., Reviriego, M., De Lope, F., \& Møller, A. P. (2007). Agerelated change in breeding performance in early life is associated with an increase in competence in the migratory barn swallow Hirundo rustica. Journal of Animal Ecology, 76(5), 915-925. https://doi.org/10.1111/j.1365-2656.2007.01269.x

Blondel, J., Dervieux, A., Maistre, M., \& Perret, P. (1991). Feeding ecology and life history variation of the blue tit in Mediterranean deciduous and sclerophyllous habitats. Oecologia, 88(1), 9-14. http://link.springer.com/article/10.1007/BF00328397

Blondel, J., Thomas, D. W., Charmantier, A., Perret, P., Bourgault, P., \& Lambrechts, M. M. (2006). A thirty-year study of phenotypic and genetic variation of blue tits in mediterranean habitat mosaics. BioScience, 56(8), 661. https://doi.org/10.1641/0006- 
Bonamour, S., Chevin, L., Charmantier, A., \& Teplitsky, C. (2019). Phenotypic plasticity in response to climate change : the importance of cue variation. Philosophical Transactions of the Royal Society B, 374: 20180178. https://doi.org/http://dx.doi.org/10.1098/rstb.2018.0178

Bonamour, S., Réale, D., Chevin, L., Teplitsky, C., \& Charmantier, A. (2020). Data from: Agedependent phenological plasticity in a wild bird. Journal of Animal Ecology. https://doi.org/10.5061/dryad.msbcc2fw8

Bouwhuis, S., Sheldon, B. C., Verhulst, S., \& Charmantier, A. (2009). Great tits growing old: selective disappearance and the partitioning of senescence to stages within the breeding cycle. Proceedings of the Royal Society B: Biological Sciences, 276(1668), 2769-2777. https://doi.org/10.1098/rspb.2009.0457

Brommer, J. E., \& Rattiste, K. (2008). “Hidden” reproductive conflict between mates in a wild bird population. Evolution, 62(9), 2326-2333. https://doi.org/10.1111/j.1558-5646.2008.00451.x

Brooks, S. P., \& Gelman, A. (1998). General methods for monitoring convergence of iterative simulations. Journal of Computational and Graphical Statistics, 7(4), 434-455.

Caro, S. P., Schaper, S. V., Hut, R. A., Ball, G. F., \& Visser, M. E. (2013). The case of the missing mechanism: how does temperature influence seasonal timing in endotherms? PLoS Biology, 11(4). https://doi.org/10.1371/journal.pbio.1001517

Charlesworth, B. (1993). Evolutionary mechanisms of senescence. Genetica, 91(1-3), 11-19.

Charmantier, Anne, Doutrelant, C., Dubuc-Messier, G., Fargevieille, A., \& Szulkin, M. (2016). Mediterranean blue tits as a case study of local adaptation. Evolutionary Applications, 9(1), 135-152. https://doi.org/10.1111/eva.12282

Charmantier, Anne, \& Gienapp, P. (2014). Climate change and timing of avian breeding and migration: evolutionary versus plastic changes. Evolutionary Applications, 7(1), 15-28. https://doi.org/doi:10.1111/eva.12126 
Chevin, L.-M., Gallet, R., Gomulkiewicz, R., Holt, R. D., \& Fellous, S. (2013). Phenotypic plasticity in evolutionary rescue experiments. Philosophical Transactions of the Royal Society of London. Series B, Biological Sciences, 368(1610), 20120089. https://doi.org/10.1098/rstb.2012.0089

Chevin, L.-M., Lande, R., \& Mace, G. M. (2010). Adaptation, plasticity, and extinction in a changing environment: towards a predictive theory. PLOS Biology, 8(4), e1000357. https://doi.org/10.1371/journal.pbio.1000357

Clutton-Brock, T. H. (1988). Reproductive success: studies of individual variation in contrasting breeding systems. (University).

Davis, M. B., Shaw, R. G., \& Etterson, J. R. (2005). Evolutionary responses to changing climate. Ecology, 86(7), 1704-1714. https://doi.org/https://doi.org/10.1890/03-0788

Dawson, A. (2008). Control of the annual cycle in birds: Endocrine constraints and plasticity in response to ecological variability. Philosophical Transactions of the Royal Society B: Biological Sciences, 363(1497), 1621-1633. https://doi.org/10.1098/rstb.2007.0004

Dewitt, T. J. (1998). Costs and limits of phenotypic plasticity : Tests with morphology and life history in a freshwater snail. Journal of Evolutionary Biology, 11, 465-480. https://doi.org/https://doi.org/10.1046/j.1420-9101.1998.11040465.x

DeWitt, T. J., \& Scheiner, S. M. (2004). Phenotypic plasticity: Functional and conceptual approaches (T. J. DeWitt \& S. M. Scheiner (eds.)). Oxford University Press.

Dingemanse, N. J., Moiron, M., Araya-Ajoy, Y. G., Mouchet, A., \& Abbey-Lee, R. N. (2020). Individual variation in age-dependent reproduction: Fast explorers live fast but senesce young? Journal of Animal Ecology, 89(2), 601-613. https://doi.org/10.1111/1365-2656.13122

Dubuc-Messier, G., Réale, D., Perret, P., \& Charmantier, A. (2016). Environmental heterogeneity and population differences in blue tits personality traits. Behavioral Ecology, 00(00), 1-12. https://doi.org/10.1093/beheco/arw148 
Dunn, P. (2004). Breeding dates and reproductive performance. Advances in Ecological Research, 35(04), 69-87. https://doi.org/10.1016/S0065-2504(04)35004-X

Ericsson, M., Henriksen, R., Bélteky, J., \& Sundman, A. (2016). Long-term and transgenerational effects of stress experienced during different life phases in chickens (Gallus gallus). PLOS ONE, 11(4), 9-12. https://doi.org/10.1371/journal.pone.0153879

Fawcett, T. W., \& Frankenhuis, W. E. (2015). Adaptive explanations for sensitive windows in development. Frontiers in Zoology, 12(Suppl 1), 1-14.

Fischer, B., van Doorn, G. S., Dieckmann, U., \& Taborsky, B. (2014). The evolution of age-dependent plasticity. The American Naturalist, 183(1), 108-125. https://doi.org/10.1086/674008

Gavrilets, S., \& Scheiner, S. M. (1993). The genetics of phenotypic of reaction norm shape V. Evolution of reaction norm shape. Journal of Evolutionary Biology, 6, 31-48.

Gelman, A., \& Rubin, D. B. (1992). Inference from iterative simulation using multiple sequences. Statistical Science, 7(4), 457-511.

Gienapp, P. (2018). The choice of the environmental covariate affects the power to detect variation in reaction norm slopes. BioRxiv, 1-19. https://doi.org/10.1101/311217

Gienapp, P., \& Brommer, J. E. (2014). Evolutionary dynamics in response to climate change. In A Charmantier, D. Garant, \& L. Kruuk (Eds.), Quantitative genetics in the wild (pp. 254-272). Oxford University Press.

Gienapp, P., Teplitsky, C., Alho, J. S., Mills, J. A., \& Merilä, J. (2007). Climate change and evolution: Disentangling environmental and genetic responses. Molecular Ecology, 17(1), 167-178. https://doi.org/10.1111/j.1365-294X.2007.03413.x

Greenwood, P. J., \& Harvey, P. H. (1982). The natal and breeding dispersal of birds. Annual Review of Ecology and Systematics. Volume 13, 1-21. 
Grieco, F., van Noordwijk, A. J., \& Visser, M. E. (2002). Evidence for the effect of learning on timing of reproduction in blue tits. Science, 296(April), 136-138. https://doi.org/10.1126/science.1068287

Hadfield, J. (2010). MCMC Methods for Multi-Response Generalized Linear Mixed Models: The MCMCgImm R Package. Journal of Statistical Software, 33(2), 1-22.

Hamilton, W. D. (1966). The moulding of senescence by natural selection. Journal of Theoretical Biology, 12(1), 12-45. https://doi.org/10.1016/0022-5193(66)90184-6

Hayward, A. D., Wilson, A. J., Pilkington, J. G., Pemberton, J. M., \& Kruuk, L. E. B. (2009). Ageing in a variable habitat: environmental stress affects senescence in parasite resistance in St Kilda Soay sheep. Proceedings of the Royal Society B: Biological Sciences, 276(1672), 3477-3485. https://doi.org/10.1098/rspb.2009.0906

Marrot, P., Charmantier, A., Blondel, J., \& Garant, D. (2018). Current Spring Warming as a Driver of Selection on Reproductive Timing in a Wild Passerine. Journal of Animal Ecology, May 2016, 111. https://doi.org/10.1111/ijlh.12426

Matthysen, E., van Overveld, T., van de Casteele, T., \& Adriaensen, F. (2010). Family movements before independence influence natal dispersal in a territorial songbird. Oecologia, 162(3), 591597. https://doi.org/10.1007/s00442-009-1483-x

Merilä, J., \& Hendry, A. P. (2014). Climate change, adaptation, and phenotypic plasticity: The problem and the evidence. Evolutionary Applications, 7(1), 1-14. https://doi.org/10.1111/eva.12137

Monaghan, P., Charmantier, A., Nussey, D. H., \& Ricklefs, R. E. (2008). The evolutionary ecology of senescence. Functional Ecology, 22(3), 371-378. https://doi.org/10.1111/j.13652435.2008.01418.x

Nussey, D. H., Coulson, T., Festa-Bianchet, M., \& Gaillard, J. M. (2008). Measuring senescence in wild animal populations: Towards a longitudinal approach. Functional Ecology, 22(3), 393-406. 
Nussey, D. H., Froy, H., Lemaitre, J. F., Gaillard, J. M., \& Austad, S. N. (2013). Senescence in natural populations of animals: Widespread evidence and its implications for bio-gerontology. Ageing Research Reviews, 12(1), 214-225. https://doi.org/10.1016/j.arr.2012.07.004

Nussey, D. H., Kruuk, L. E. B., Morris, A., \& Clutton-Brock, T. H. (2007). Environmental conditions in early life influence ageing rates in a wild population of red deer. Current Biology, 17(23), 10001001. https://doi.org/10.1016/j.cub.2007.10.005

Nussey, D. H., Wilson, A. J., \& Brommer, J. E. (2007). The evolutionary ecology of individual phenotypic plasticity in wild populations. Journal of Evolutionary Biology, 20(3), 831-844. https://doi.org/10.1111/j.1420-9101.2007.01300.x

Parmesan, C., \& Yohe, G. (2003). A globally coherent fingerprint of climate change impacts across natural systems. Nature, 421(6918), 37-42. https://doi.org/10.1038/nature01286

Perrins, C. M., \& McCleery, R. H. (1989). Laying date and clutch size in the great tit. Wilson Bulletin, 101(2), 236-253. http://elibrary.unm.edu/sora/Wilson/v101n02/p0236-p0253.pdf

Pigliucci, M. (2001). Phenotypic plasticity: beyond nature and nurture (John Hopkins University Press (ed.)).

Porlier, M., Charmantier, A., Bourgault, P., Perret, P., Blondel, J., \& Garant, D. (2012). Variation in phenotypic plasticity and selection patterns in blue tit breeding time: Between- and withinpopulation comparisons. Journal of Animal Ecology, 81(5), 1041-1051. https://doi.org/10.1111/j.1365-2656.2012.01996.x

Radchuk, V., Reed, T., Teplitsky, C., van de Pol, M., Charmantier, A., Hassall, C., Adamík, P., Adriaensen, F., Ahola, M. P., Arcese, P., Miguel Avilés, J., Balbontin, J., Berg, K. S., Borras, A., Burthe, S., Clobert, J., Dehnhard, N., de Lope, F., Dhondt, A. A., ... Kramer-Schadt, S. (2019). Adaptive responses of animals to climate change are most likely insufficient. Nature 
454

455

456

Ramakers, J. J. C., Gienapp, P., \& Visser, M. E. (2018). Phenological mismatch drives selection on elevation, but not on slope, of breeding time plasticity in a wild songbird. Evolution, 175-187. https://doi.org/10.1111/evo.13660

Reed, T. E., Schindler, D. E., \& Waples, R. S. (2011). Integrating effects of phenotypic plasticity and evolution on population persistence in a changing climate. Conservation Biology, 25(1), 56-63. https://doi.org/10.1111/j.1523-1739.2010.01552.x

Reed, T. E., Waples, R. S., Schindler, D. E., Hard, J. J., \& Kinnison, M. T. (2010). Phenotypic plasticity and population viability: the importance of environmental predictability. Proceedings of the Royal Society B: Biological Sciences, 277(1699), 3391-3400. https://doi.org/10.1098/rspb.2010.0771

Ricklefs, R. E. (2008). The evolution of senescence from a comparative perspective. Functional Ecology, 22(3), 379-392. https://doi.org/10.1111/j.1365-2435.2008.01420.x

Stamps, J. A., \& Krishnan, V. V. (2017). Age-dependent changes in behavioural plasticity: insights from Bayesian models of development. Animal Behaviour, 126, 53-67. https://doi.org/10.1016/j.anbehav.2017.01.013

van de Pol, M., Osmond, H. L., \& Cockburn, A. (2012). Fluctuations in population composition dampen the impact of phenotypic plasticity on trait dynamics in superb fairy-wrens. Journal of Animal Ecology, 81(2), 411-422. https://doi.org/10.1111/j.1365-2656.2011.01919.x

van de Pol, M., \& Wright, J. (2009). A simple method for distinguishing within- versus betweensubject effects using mixed models. Animal Behaviour, 77(3), 753-758. https://doi.org/10.1016/j.anbehav.2008.11.006

Van Noordwijk, A. J., McCleery, R. H., \& Perrins, C. M. (1995). Selection for the timing of great tit breeding in relation to caterpillar growth and temperature. Journal of Animal Ecology, 64(4), 
van Tienderen, P. H., \& Koelewijn, H. P. (1994). Selection on reaction norms, genetic correlations and constraints. Genet. Res., Camb., 64, 115-125.

Vedder, O., Bouwhuis, S., \& Sheldon, B. C. (2013). Quantitative assessment of the importance of phenotypic plasticity in adaptation to climate change in wild bird populations. PLoS Biology, 11(7), 1-10. https://doi.org/10.1371/journal.pbio.1001605

Visser, M. E. (2008). Keeping up with a warming world; assessing the rate of adaptation to climate change. Proceedings of the Royal Society B: Biological Sciences, 275(1635), 649. https://doi.org/10.1098/rspb.2007.0997

Visser, M. E., \& Both, C. (2005). Shifts in phenology due to global climate change: the need for a yardstick. Proceedings of the Royal Society B: Biological Sciences, 272(1581), 2561-2569. https://doi.org/10.1098/rspb.2005.3356

Visser, M. E., Holleman, L. J. M., \& Caro, S. P. (2009). Temperature has a causal effect on avian timing of reproduction. Proceedings of the Royal Society B: Biological Sciences, 276(1665), 2323-2331. https://doi.org/10.1098/rspb.2009.0213

Walther, G. R., Post, E., Convey, P., Menzel, A., Parmesan, C., Beebee, T. J. C., Fromentin, J. M., Hoegh-Guldberg, O., \& Bairlein, F. (2002). Ecological responses to recent climate change. Nature, 416(6879), 389-395. https://doi.org/10.1038/416389a

Warner, D. A., Miller, D. A. W., Bronikowski, A. M., \& Janzen, F. J. (2016). Decades of field data reveal that turtles senesce in the wild. PNAS, 113(23). https://doi.org/10.1073/pnas.1600035113

West-Eberhard, M. J. (2003). Developmental plasticity and evolution (Oxford Uni).

Williams, G. C. (1957). Pleiotropy, natural selection, and the evolution of senescence. Evolution, 11(4), 398-411. 
501 All experimental protocols described here were approved by the ethics committee for animal 502 experimentation of Languedoc Roussillon (305-CEEA-LR-12066 approved in 2012 and 2018) as well as 503 by Regional Institutions (bylaw issued by the Prefecture on 08/12/2015 n 2015-491). Captures and 504 bird ringing were performed under a personal ringing permit delivered by the CRBPO (Centre de 505 Recherches par le Baguage des Populations d'Oiseaux) to Anne Charmantier (ringing permit number 506 1907).

507

\section{Data accessibility}

Data available from the Dryad Digital Repository: https://doi.org/10.5061/dryad.msbcc2fw8

\section{Author's contributions}

C.T., A.C., L.-M.C. and S.B. designed the research. A.C., C.T. and S.B. (and many other contributors) collected field data. S.B. conducted statistical analyses. S.B., C.T., L.-M.C., A.C., D.R. wrote the paper.

\section{Competing interests}

We declare we have no competing interests.

\section{Acknowledgments}

We thank Andy Russel and Patrice David for useful discussions. We also thank Maxime Dubart for useful advice for the statistical analyses. We thank all the people who helped maintain the study site and conduct the blue tit monitoring in the past 45 years, in particular Jacques Blondel, Phillippe Perret, Marcel Lambrechts, Claire Doutrelant, Christophe de Franceschi (who also managed the database), Annick Lucas and Pablo Giovannini. We thank the APEEM, the ONF and Achille Sanroma for field logistics, and the Fango valley MAB reserve. 
522 This project was funded by a long-term support by the OSU-OREME, and by the European Research

523 Council (Starting grant ERC-2013-StG-337365-SHE to AC).

524 Tables and Figures

525 Table 1: Model 1 for laying date.

526 Laying date variation according to temperature and age. Results are from the mixed model 1

527 implemented with MCMCgImm on 1696 laying date observations from 854 females. Posterior modes

528 of estimates are indicated together with $95 \%$ credible intervals. Fixed effect estimates with $95 \%$

529 credible intervals that do not include zero are represented in bold. ALR = age at last reproduction.

\begin{tabular}{|l|l|l|l|}
\hline Term & Posterior mode & Lower 95\%Cl & Upper 95\%Cl \\
\hline \multicolumn{4}{|c|}{ Fixed effects } \\
\hline Intercept $(\boldsymbol{\mu})$ & $\mathbf{1 3 4 . 1 4}$ & $\mathbf{1 3 2 . 3 9}$ & $\mathbf{1 3 5 . 3 6}$ \\
\hline Temperature $\left(\boldsymbol{\alpha}_{\mathbf{1}}\right)$ & $\mathbf{- 2 . 9 2}$ & $\mathbf{- 4 . 7 9}$ & $\mathbf{- 1 . 6 2}$ \\
\hline Age $\left(\boldsymbol{\alpha}_{\mathbf{2}}\right)$ & $\mathbf{- 3 . 4 3}$ & $\mathbf{- 3 . 8 7}$ & $\mathbf{- 2 . 8 1}$ \\
\hline Age $\left(\boldsymbol{\alpha}_{3}\right)$ & $\mathbf{0 . 4 0}$ & $\mathbf{0 . 3 3}$ & $\mathbf{0 . 5 0}$ \\
\left.\hline${\text { Temperature : Age }\left(\boldsymbol{\alpha}_{\mathbf{4}}\right)}^{\mathbf{2}}\right)$ & $-\mathbf{0 . 7 3}$ & $\mathbf{- 1 . 3 1}$ & $\mathbf{- 0 . 0 7}$ \\
\hline Temperature : Age ${ }^{2}\left(\alpha_{5}\right)$ & 0.06 & -0.03 & 0.15 \\
\hline ALR $\left(\alpha_{6}\right)$ & -0.22 & -0.43 & 0.02 \\
\hline \multicolumn{4}{|c|}{ Random effects } \\
\hline Year & 13.80 & 8.77 \\
\hline Ind & 10.90 & 9.05 & 22.49 \\
\hline Residuals $\left(\varepsilon_{i j}\right)$ & 14.37 & 13.14 & 13.40 \\
\hline
\end{tabular}


Table 2: Model 2 for annual reproductive success.

Annual reproductive success variation according to laying date (LD) and age. Results are from the mixed model 2 implemented with MCMCgImm on 1092 laying date observations from 667 females. Posterior modes of estimates are represented together with $95 \%$ credible intervals. Fixed effect estimates with 95\% credible intervals that do not include zero are represented in bold.

\begin{tabular}{|l|l|l|l|}
\hline \multicolumn{5}{|l|}{ Term } & Posterior mode & Lower 95\%Cl & Upper 95\%Cl \\
\hline \multicolumn{4}{|c|}{ Fixed effects } \\
\hline Intercept $(\gamma)$ & $\mathbf{3 . 8 4}$ & $\mathbf{2 . 7 6}$ & $\mathbf{5 . 2 5}$ \\
\hline Age $\left(\beta_{1}\right)$ & -0.37 & -0.64 & 0.15 \\
\hline Age $^{2}\left(\boldsymbol{\beta}_{2}\right)$ & $-\mathbf{0 . 0 1}$ & $-\mathbf{0 . 0 3}$ & $\mathbf{- 0 . 0 0 2}$ \\
\hline LD $\left(\boldsymbol{\beta}_{3}\right)$ & $-\mathbf{0 . 0 2}$ & $-\mathbf{0 . 0 3}$ & $-\mathbf{0 . 0 1}$ \\
\hline Age ${ }^{*}$ LD $\left(\beta_{4}\right)$ & 0.002 & -0.0003 & 0.006 \\
\hline \multicolumn{5}{|l|}{ Random effects } \\
\hline Year & 0.08 & 0.05 & 0.14 \\
\hline Ind & 0.03 & 0.03 & 0.04 \\
\hline Residuals $\left(r_{i j}\right)$ & 0.03 & 0.02 & 0.04 \\
\hline
\end{tabular}


Figure 1: Age-dependent reaction norm of laying date with respect to temperature.

Age-dependent reaction norm of laying date with respect to mean-centered temperature. a) Bivariate reaction norm representing predicted laying date (vertical axis and colour gradient) against temperature and age. Also represented are the univariate reaction norms with respect to the environment showing plasticity at age 1 (dotted line) and 5 (long dashed line). b) Reaction norms of predicted laying date with respect to temperature at age 1 (dotted line) and 5 (long dashed line, same as Figure 1a) are shown together with the average reaction norm across all females regardless of age (solid line). For a and b, predicted values of laying date were obtained from the posterior mode of predictions across all iterations from model 1. Predictions were estimated for all combinations of temperature (from -2.5 to +1.5 degree around the average cue temperature) and age (from 1 to 9 years old). c) Median reaction norm intercept (in grey) and slope (in black) of laying date with respect to temperature are plotted against female age (over its observed range). The slope was estimated as $\alpha_{1}+\alpha_{4} A_{i j}+\alpha_{5} A_{i j}^{2}$ (model 1 and Table 1$)$.
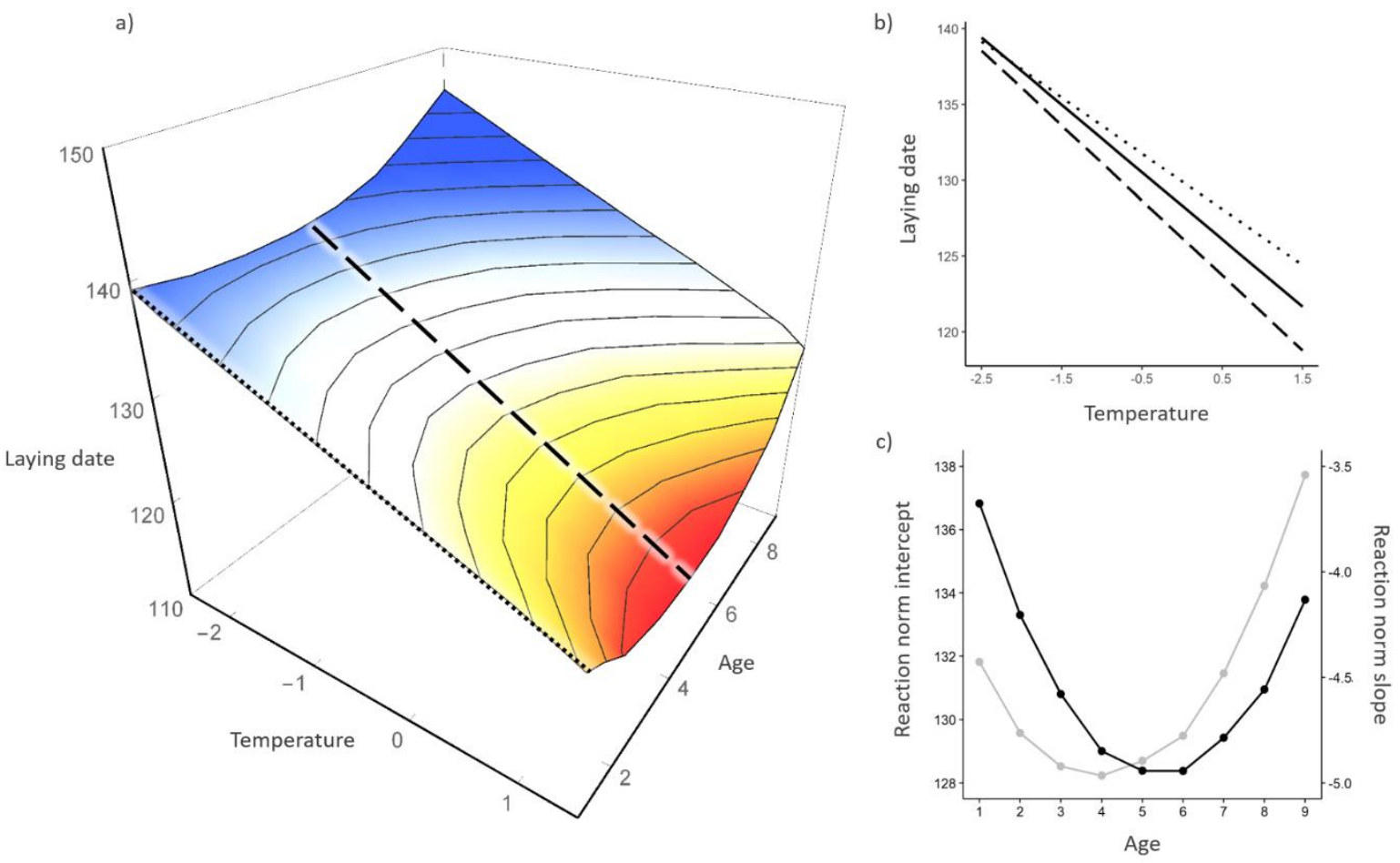
Figure 2: Influence of age and phenology on annual reproductive success.

Average annual reproductive success ( \pm standard error) plotted according to a) age categories, or to b) laying date for different female age categories. In b), the slopes of average annual reproductive success with respect to laying date are significantly negative for the three first age classes (slope= $0.05[\mathrm{SE}=0.02, \mathrm{p}$-value $=0.01],-0.08[\mathrm{SE}=0.01, \mathrm{p}$-value $=4.88 \mathrm{e}-08]$, and $-0.06[\mathrm{SE}=0.01, \mathrm{p}$-value $=1.99 \mathrm{e}-$ 05], for 1-year-old, 2-3 year-old, and 4-5 year-old females, respectively), but not for the oldest females of 6 and more years old (slope $=0.01[\mathrm{SE}=0.03, \mathrm{p}$-value $=0.67]$ ). Annual reproductive success is estimated as the number of fledglings per breeding attempt in the year. Note that some points have no standard error bars because of a single observation in the laying date - age class combination.

a)

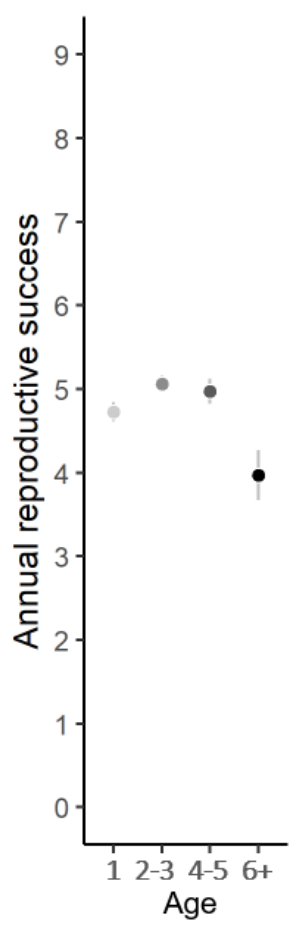

b)

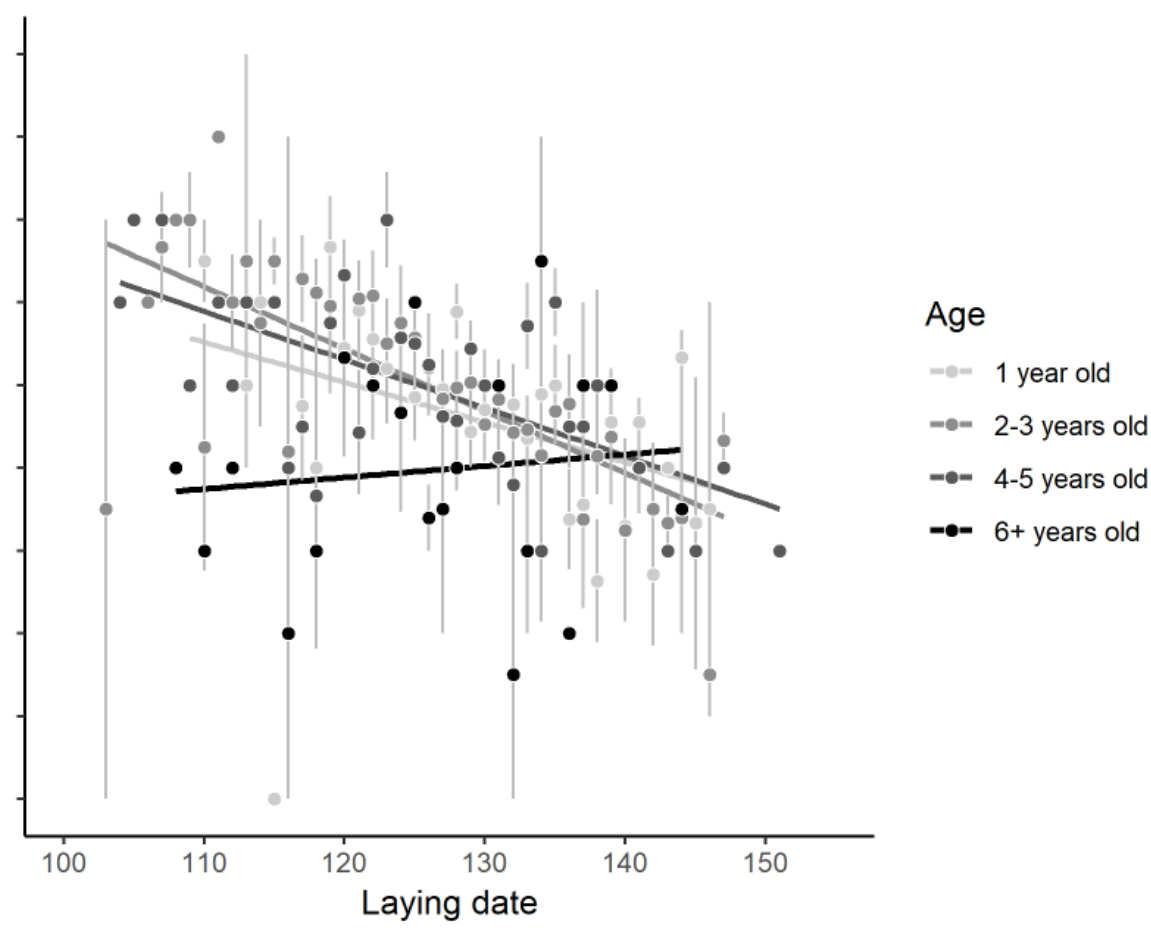

